\title{
The efficacy and safety of crizotinib in the treatment of anaplastic lymphoma kinase-positive non-small cell lung cancer: a meta-analysis of clinical trials
}

\author{
Haili Qian ${ }^{1 \dagger}$, Feng Gao ${ }^{3 \dagger}$, Haijuan Wang ${ }^{1}$ and Fei Ma ${ }^{2 *}$
}

\begin{abstract}
Background: Crizotinib was granted accelerated approval by the Food and Drug Administration in 2011 for the treatment of anaplastic lymphoma kinase (ALK)-positive non-small cell lung cancer (NSCLC). To evaluate the efficacy and safety of crizotinib, we performed a meta-analysis of published clinical trials using the random effect model.

Methods: The efficacy and safety of crizotinib was evaluated based on 1-year overall survival (OS), progression-free survival (PFS), overall response rate (ORR), partial response, complete response, stable disease, and dose reduction or cessation because of crizotinib toxicity.

Results: Six clinical trials were included in the meta-analysis. Crizotinib treatment demonstrated a 1-year OS of 66.8\% (95\% Cl, 52.2-78.8\%) and a PFS of 8.6 months (95\% Cl, 7.3-9.9 months). The aggregate ORR, partial response and complete response rates were $61.2 \%, 59.8 \%$ and $1.5 \%$, respectively. The proportion of patients achieving stable disease was $42.6 \%(95 \% \mathrm{Cl}, 17.3-72.5 \%)$. The most frequently reported adverse effects of crizotinib were mild visual disturbances, nausea, vomiting, diarrhea, constipation, edema, reduction in glomerular filtration rate, and generally reversible but sometimes severe elevations in aspartate aminotransferase and alanine aminotransferase. The proportion of patients who required dose reduction or cessation because of crizotinib toxicity was $6.5 \%(95 \% \mathrm{Cl}, 4.1-10.1 \%)$.

Conclusions: This meta-analysis revealed extended survival and improved response rates in patients treated with crizotinib. As a novel, targeted anticancer agent, crizotinib appears to be a favorable treatment option for patients with locally advanced or metastatic ALK-positive NSCLC.
\end{abstract}

Keywords: Meta-analysis, Crizotinib, Anaplastic lymphoma kinase (ALK), Non-small cell lung cancer (NSCLC)

\section{Background}

Lung cancer, of which approximately $85-90 \%$ of cases are non-small cell lung cancer (NSCLC), is the most common fatal malignancy among all cancers worldwide, and its incidence has gradually increased over recent decades, [1,2]. Patients usually present with unresectable locally advanced (stage IIIB) or distant metastases (stage IV) NSCLC. For patients newly diagnosed with advanced NSCLC, the median overall survival (OS) with platinum-

\footnotetext{
* Correspondence: mafei2011@139.com

${ }^{\dagger}$ Equal contributors

${ }^{2}$ Department of Medical Oncology, Cancer Institute/Hospital, Peking Union Medical College \& Chinese Academy of Medical Sciences, Beijing, China
} Full list of author information is available at the end of the article based chemotherapy is 7.4-9.9 months, and the median OS with combined chemotherapy and bevacizumab is 12.5 months. Median progression-free survival (PFS) with second-line chemotherapy, such as pemetrexed and docetaxel, is approximately 2.2-2.9 months. Although associated with a higher response rate, OS with gefitinib is similar to that of standard carboplatin plus paclitaxel chemotherapy [3]. The 5-year survival rate of NSCLC is lower than 20\% [4,5]. However, despite the relatively poor prognosis for NSCLC patients, the development of treatments for NSCLC has not yet kept pace [6].

In recent years, the identification of genetic abnormalities that may underlie oncogenic development and progression have revolutionized oncology research [7]. A 
translocation in the gene encoding the receptor tyrosine kinase anaplastic lymphoma kinase (ALK), leading to the expression of ALK fusion proteins, was first reported in NSCLC patients in 2007 [8,9]. The activated ALK fusion proteins result in aberrant ALK signaling and oncogenic transformation through several molecular signaling pathways, including PI3K/AKT/mTOR, JAK/STAT, and RAS/ MEK/ERK [10]. Constitutive ALK signaling mediates enhanced cell proliferation, cell survival, and metabolism. ALK gene rearrangements are found in approximately 2$7 \%$ of unselected patients with NSCLC [11]. Because of the role of ALK in oncogenesis, tyrosine kinase inhibition has been investigated as a therapeutic approach [11]. Crizotinib is a small-molecule selective inhibitor of ALK and mesenchymal epithelial growth factor (c-Met)/hepatocyte growth factor receptor (HGFR) kinases [12]. It was approved via accelerated drug approval by the US Food and Drug Administration in 2011, based on the findings of two early phase clinical trials demonstrating prolonged progression-free survival (PFS; 6-10 months) and high response rates $(50-57 \%)$ in patients with ALK-positive NSCLC $[13,14]$. A further phase 3 clinical trial in patients with ALK-positive NSCLC confirmed the advantage of crizotinib in survival, response rates, and duration of response in ALK-positive patients with NSCLC, although mild to severe adverse effects, commonly reported as gastrointestinal disturbances (nausea, diarrhea, vomiting, and constipation), visual disturbances and fatigue, were noted $[15,16]$.

This study systematically combines data from published clinical trials to evaluate the efficacy and safety of crizotinib in the treatment of ALK-positive NSCLC using a random effect model following the Preferred Reporting Items for Systematic Reviews and Meta-Analyses (PRISMA) guidelines [17].

\section{Methods}

\section{Search strategy for the identification of studies}

To evaluate the efficacy and safety of crizotinib in the treatment of ALK-positive NSCLC, PubMed, Embase, and the Cochrane Library (all from 1980 to Nov 2013) were searched to identify clinical trials in English-language journals. The search terms used were "crizotinib", "non-small cell lung cancer", "carcinoma", "anaplastic lymphoma kinase", and "clinical trial" in various combinations. We also manually searched the related references from the bibliography of the selected articles. Only eligible original studies with full text available were selected, and meeting abstracts were excluded. The corresponding authors of some studies were contacted for further information if necessary.

\section{Article selection criteria}

All clinical trials exploring the efficacy and safety of crizotinib in the treatment of ALK-positive NSCLC were considered eligible for the analysis. The inclusion criteria were as follows: (i) articles were clinical trials investigating the efficacy and/or safety of crizotinib in the treatment of ALK-positive NSCLC; (ii) a standardized effect size could be calculated on the evaluations of 1-year overall survival (OS), progression-free survival (PFS), overall response rate (ORR), partial response, complete response, stable disease, and/or dose reduction or cessation because of adverse effects of crizotinib were reported; (iii) articles were in English; and (iv) full text was available. Two investigators ( $\mathrm{MF}$ and $\mathrm{WH}$ ) independently assessed the articles for relevancy.

\section{Data extraction}

All articles were first de-identified (article title, author names, journal name and year of publication) before selection. The abstracts of the articles were independently reviewed by two authors (MF and WH). Outcomes were pooled for 1-year OS (defined as the percentage of patients who remained alive 1 year after crizotinib treatment), ORR (defined as the observed alive rate of patients since the date of crizotinib treatment), partial response (defined as the percentage of patients who had a decrease in the size of tumor, or in the extent of cancer in the body, in response to crizotinib treatment), complete response (defined as the percentage of patients who had the disappearance of all signs of cancer in response to crizotinib treatment), dose reduction or cessation because of adverse effects of crizotinib, and mean duration of PFS and stable disease. Data were filtered and transferred into a standard electronic form. Any discrepancies were resolved by discussion until a consensus was reached. If not, the principal investigator $(\mathrm{QH})$ made the final decision on the eligibility of the study and data extraction.

\section{Statistical analysis}

Data management and analysis were performed using Comprehensive Meta-analysis Version 2 (Biostat, Englewood, NJ, USA). Data were pooled statistically using the event rates calculated for primary (the 1-year OS, ORR, partial response, complete response) and secondary endpoints (dose reduction or cessation because of crizotinib adverse effects, and mean duration of PFS and stable disease).

A random effect meta-analysis was conducted to investigate the efficacy and safety of crizotinib in the treatment of ALK-positive NSCLC in this study. Because fixed effects models in meta-analysis assume that one true effect exists, which all studies are estimating, they increase the risk of a Type I error and create overly narrow confidence intervals. In contrast, random effects models assume that true effects are different across studies owing to heterogeneity of patients, treatments or other factors. Random 
effects models create wider confidence intervals and minimize the risk of Type I error. Therefore, random effects models are recommended to be routinely employed in meta-analysis, particularly when study heterogeneity is expected or found [18].

The measure of heterogeneity was evaluated using Cochran's Q-test. Additionally, heterogeneity was assessed using the $\mathrm{I}^{2}$ statistic. A high value for $\mathrm{I}^{2}$ indicates heterogeneity. Publication bias was evaluated using Egger's test.

\section{Ethical approval}

The study was approved by the Ethics Committee of the Cancer Hospital of Chinese Academy of Medical Sciences.

\section{Results}

A total of 87 abstracts were initially selected through database searching, and 63 articles were excluded because they failed to meet the criteria. For the remaining 24 articles, five had the same data presented in other studies, six did not provide sufficient information to calculate an effect size, and seven studies were case reports. The article selection process is shown in Figure 1, and details of the six articles [14,19-23] selected for our analysis are shown in Table 1.

In these 6 studies, the efficacy and toxicity of crizotinib was investigated in the treatment of ALK-positive NSCLC. Analysis of pooled data revealed a 1-year OS of 66.8\% (95\% CI, 52.2-78.8\%; Figure 2A) and a PFS of 8.6 months (95\% CI, 7.3-9.9 months; Figure 2B). In terms of response rates, the aggregate ORR (Figure 3A), partial response (Figure 3B) and complete response (Figure 3C) were $61.2 \%$ (95\% CI, 57.4-64.8\%), 59.8\% (95\% CI, 56.0-63.5\%) and 1.5\% (95\% CI, $0.8-2.8 \%)$, respectively. The proportion of patients achieving stable disease (Figure 3D) was 42.6\% (95\% CI, 17.3-72.5\%). The proportion of patients who required dose reduction or cessation because of crizotinib toxicity was 6.5\% (95\% CI, 4.1-10.1\%, Figure 4).

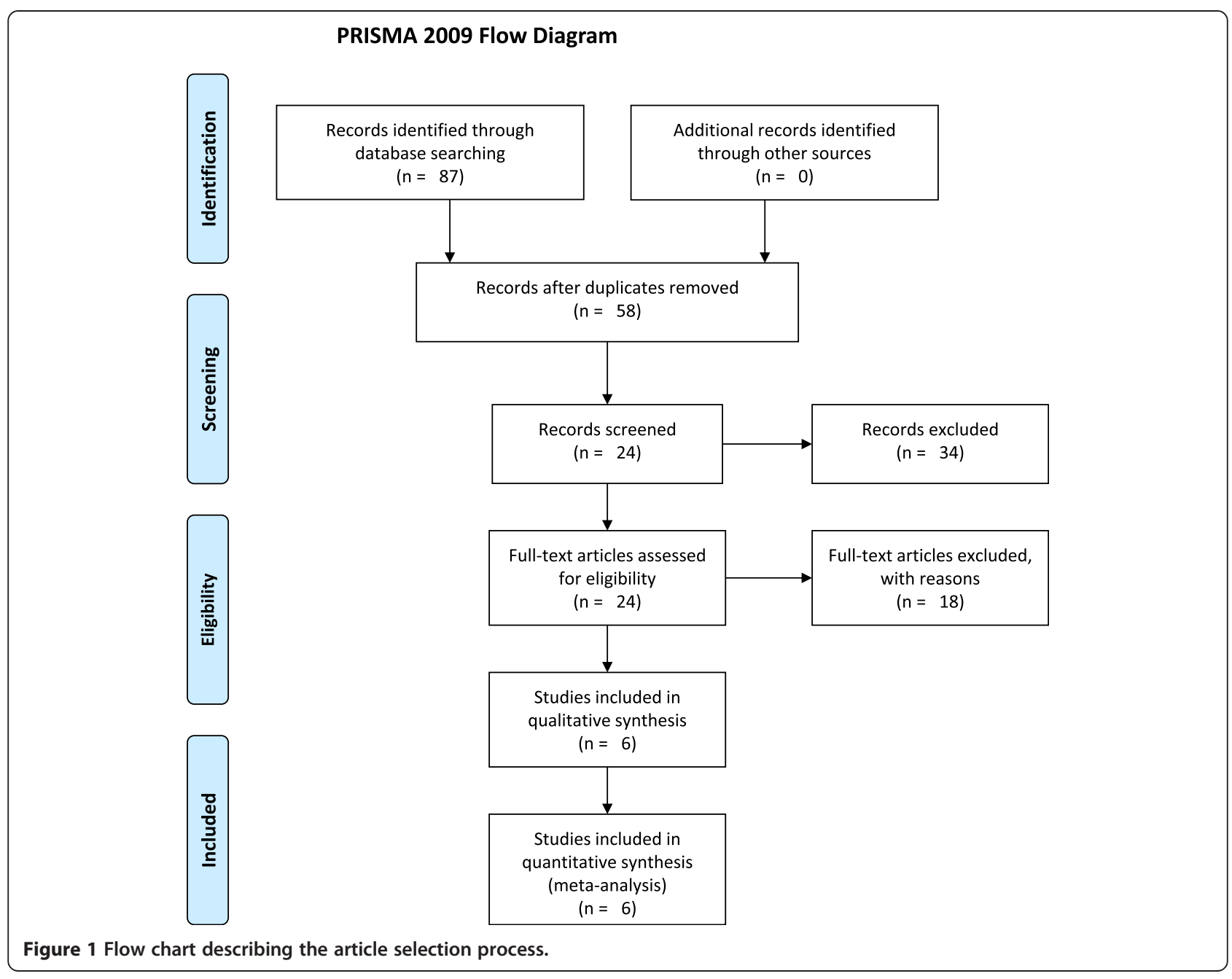


Table 1 Main characteristics of the selected studies

\begin{tabular}{llllllll}
\hline Citation & $\begin{array}{l}\text { Mean age } \\
\text { (years) }\end{array}$ & $\begin{array}{l}\text { Number of } \\
\text { patients }\end{array}$ & $\begin{array}{l}\text { Duration of } \\
\text { follow up } \\
\text { (month) }\end{array}$ & $\begin{array}{l}\text { Dose and frequency of } \\
\text { crizotinib } \\
\text { administration }\end{array}$ & $\begin{array}{l}\text { Trial } \\
\text { phase }\end{array}$ & $\begin{array}{l}\text { Tumor histologic type } \\
\text { (Adenocarcinoma, \%) }\end{array}$ & $\begin{array}{l}\text { Extent of } \\
\text { disease } \\
\text { (Metastatic, \%) }\end{array}$ \\
\hline Shaw et al. [21] & 50.0 & 173 & 12.2 & 250 mg twice daily & Phase 3 & 95 & 95 \\
Brosnan et al. [22] & 54.7 & 38 & 16.3 & 250 mg twice daily & NA & NA & NA \\
Riely [23] & 53.0 & 261 & 12.0 & 250 mg twice daily & Phase 2 & 92 & NA \\
Camidge et al. [19] & 52.0 & 149 & 16.3 & 250 mg twice daily & Phase 1 97 & NA \\
Shaw et al. [20] & 51.0 & 56 & 18.0 & 250 mg twice daily & Phase 1 96 & NA \\
Kwak et al. [14] & 51.0 & 82 & 6.4 & 250 mg twice daily & Phase 1 96 & \\
\hline
\end{tabular}

$\mathrm{NA}=$ not applicable.

There were statistically significant differences for 1 -year OS $\left(\mathrm{Q}=14.903, p=0.002, \mathrm{I}^{2}=79.870\right)$ and stable disease $\left(\mathrm{Q}=122.520, p<0.001, \mathrm{I}^{2}=97.551\right)$. No significant difference was observed for other outcomes $(p>0.05)$. Funnel plots and Egger's regression test revealed no significant publication bias $(p>0.05)$.

\section{Discussion}

The goal of this meta-analysis was to evaluate the efficacy and safety of crizotinib in the treatment of ALK-positive NSCLC. The aggregated effect size revealed that crizotinib treatment shows generally extended survival (1-year OS: 66.8\%; PFS: 8.6 months) and improved response rates (ORR: 61.2\%; partial response: 59.8\%; complete response: $1.5 \%$; stable disease: $42.6 \%$ ). These findings strongly indicate the effectiveness of crizotinib treatment in patients with ALK-positive NSCLC. In a retrospective analysis of a phase 1 trial [20], ALK-positive patients who received crizotinib $(\mathrm{n}=82)$ showed improved survival compared to ALK-positive control patients $(\mathrm{n}=36)$ who did not receive crizotinib. In the second- and third-line settings, 1-year OS was $70 \%$ versus $44 \%$, respectively; and 2-year OS was $55 \%$ versus $12 \%$, respectively. The effect of crizotinib treatment $(\mathrm{n}=173)$ was also compared with standard-of-care
NSCLC treatments (docetaxel or pemetrexed as a single agent, $\mathrm{n}=174$ ) in ALK-positive patients with advanced NSCLC previously treated with one platinum-containing regimen in a Phase 3 trial [21]. Results showed that PFS was prolonged in the crizotinib-treated group (7.7 months vs. 3.3 months, $p<0.0001)$. Patients in the crizotinib arm completed more treatment cycles than those in the standard chemotherapy arm. Response was significantly improved $(65 \%$ vs. $20 \%, p<0.0001)$. Thus, crizotinib treatment demonstrated an improvement in survival and response rates, which were superior to standard-ofcare chemotherapy. As a novel targeted anticancer agent, crizotinib appears to be a favorable treatment option for patients with locally advanced or metastatic ALK-positive NSCLC.

Notably, $6.5 \%$ of patients have to reduce the dose or discontinue crizotinib treatment because of toxicity. In the studies included in this meta-analysis, the most frequently reported adverse effects were mild visual disturbances, nausea, vomiting, diarrhea, constipation, edema, reduction in glomerular filtration rate, and generally reversible but sometimes severe elevations in aspartate aminotransferase and alanine aminotransferase. Shaw et al. [21] found that adverse events reported with crizotinib treatment of ALK- 


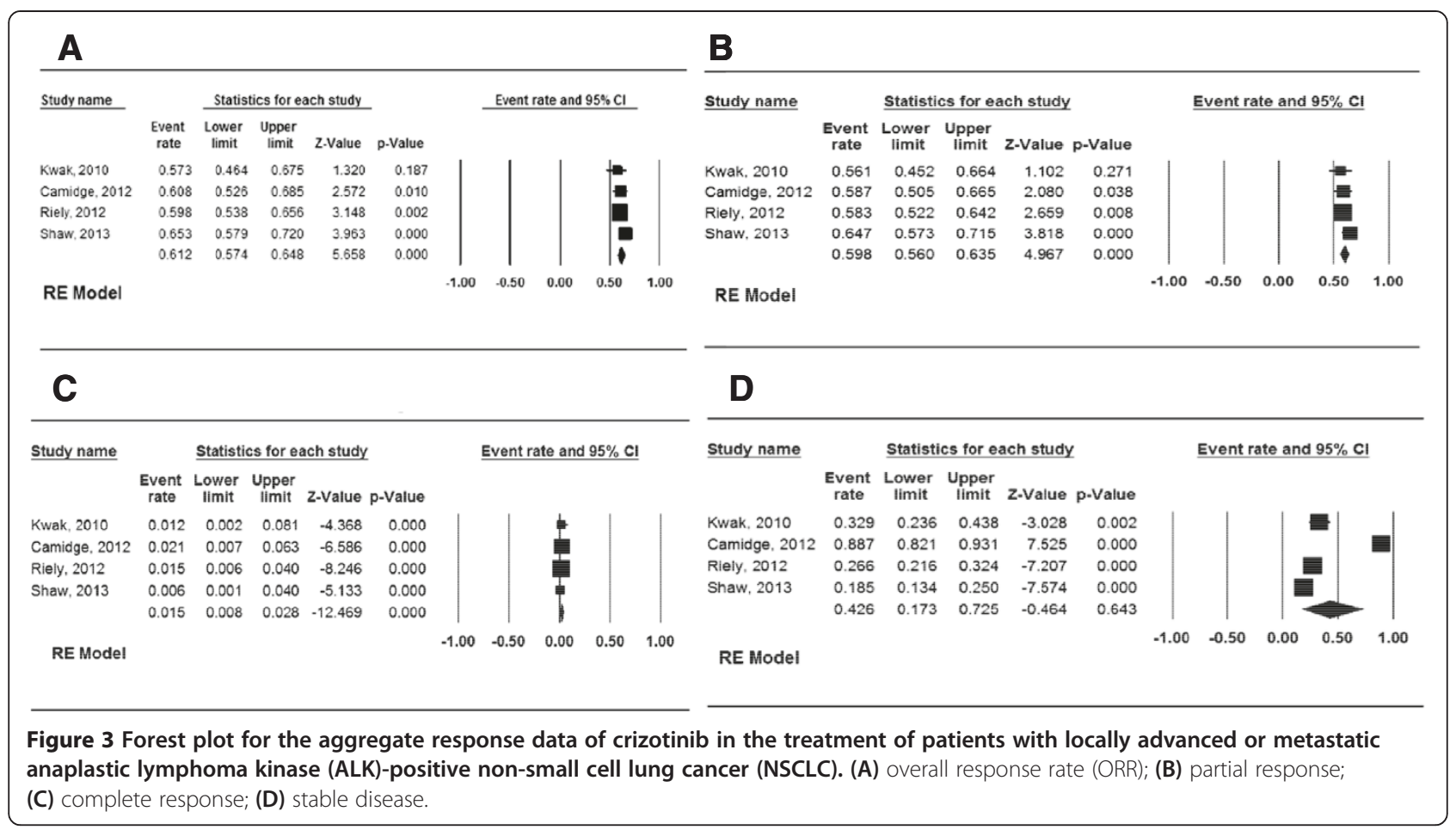

positive NSCLC patients were comparable to docetaxel or pemetrexed, with similar severe (grade 3 or 4 ) reactions across the treatment groups. Discontinuation rates were slightly higher in the chemotherapy arm (10\%) compared with the crizotinib arm (6\%). Although generally tolerated, the toxicity of crizotinib should be monitored in order to maximize its safety [24,25], and the dose of crizotinib needs to be adjusted when necessary [26].

As a newly approved medication, evidence of the efficacy and safety of crizotinib in the treatment of ALKpositive NSCLC is relatively incomplete. The findings from this meta-analysis are therefore valuable for physicians and public health policy makers in formulating strategies to maximize the efficacy and minimize crizotinib toxicity. However, given the relatively small numbers of cases included into the trials, generalization of the conclusions from this study to all patients with ALKpositive NSCLC should be cautious.

\section{Conclusions}

In conclusion, the meta-analysis investigated the efficacy and safety of crizotinib in the treatment of patients with locally advanced or metastatic ALK-positive NSCLC. Clinical trials with crizotinib treatment show extended survival and improved response rates, along with tolerable toxicity. As a novel targeted anticancer agent, crizotinib appears to be a favorable treatment option for patients with locally advanced or metastatic ALK-positive NSCLC. Further blinded, placebo-controlled studies with larger sample sizes are needed to compare the efficacy and safety of crizotinib with other NSCLC treatments.

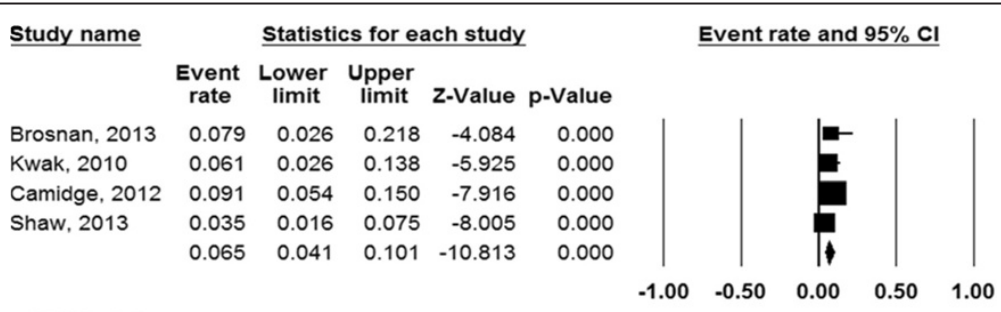

RE Model

Figure 4 Forest plot for the aggregate proportion of patients who required dose reduction or cessation because of crizotinib toxicity in the treatment of locally advanced or metastatic anaplastic lymphoma kinase (ALK)-positive non-small cell lung cancer (NSCLC). 


\section{Competing interests}

The authors declare that they have no competing interests.

\section{Authors' contributions}

FM carried out the study and drafted the manuscript. HW participated in the extraction and analysis of data. HQ and FG conceived of the study, and participated in its design and coordination and helped to draft the manuscript. All authors read and approved the final manuscript.

\section{Acknowledgements}

This manuscript was reviewed by Dr. Tao Wen for design and language preparation. We greatly appreciate his support.

\section{Author details}

${ }^{1}$ State Key Laboratory of Molecular Oncology, Cancer Institute/Hospital, Peking Union Medical College \& Chinese Academy of Medical Sciences, Beijing, China. '2Department of Medical Oncology, Cancer Institute/Hospital, Peking Union Medical College \& Chinese Academy of Medical Sciences, Beijing, China. ${ }^{3}$ Health Division of Guard Bureau, General Staff Department of Chinese PLA, Beijing, China.

Received: 25 April 2014 Accepted: 9 September 2014

Published: 19 September 2014

\section{References}

1. Weinmann M, Jeremic B, Toomes H, Friedel G, Bamberg M: Treatment of lung cancer in the elderly. Part I: non-small cell lung cancer. Lung Cancer 2003, 39(3):233-253.

2. Roberts PJ: Clinical use of crizotinib for the treatment of non-small cell lung cancer. Biologics 2013, 7:91-101.

3. Fukuoka M, Wu YL, Thongprasert S, Sunpaweravong P, Leong SS, Sriuranpong V, Chao TY, Nakagawa K, Chu DT, Saijo N, Duffield EL, Rukazenkov Y, Speake G, Jiang H, Armour AA, To KF, Yang JC, Mok TS: Biomarker analyses and final overall survival results from a phase III, randomized, open-label, first-line study of gefitinib versus carboplatin/ paclitaxel in clinically selected patients with advanced non-small-cell lung cancer in Asia (IPASS). J Clin Oncol 2011, 29(21):2866-2874.

4. Klastersky J, Paesmans M: Response to chemotherapy, quality of life benefits and survival in advanced non-small cell lung cancer: review of literature results. Lung Cancer 2001, 34(Suppl 4):S95-S101.

5. American Cancer Society: Cancer Facts \& Figures 2013. 2013. http://www. cancer.org/research/cancerfactsstatistics/cancerfactsfigures2013/.

6. Bowles DW, Weickhardt AJ, Doebele RC, Camidge DR, Jimeno A: Crizotinib for the treatment of patients with advanced non-small cell lung cancer. Drugs Today (Barc) 2012, 48(4):271-282.

7. Kanteti R, El-Hashani E, Dhanasingh I, Tretiakova M, Husain AN, Sharma S, Sharma J, Vokes EE, Salgia R: Role of PAX8 in the regulation of MET and RON receptor tyrosine kinases in non-small cell lung cancer. BMC Cancer 2014, 14:185.

8. Soda M, Choi YL, Enomoto M, Takada S, Yamashita Y, Ishikawa S, Fujiwara S, Watanabe H, Kurashina K, Hatanaka H, Bando M, Ohno S, Ishikawa Y, Aburatani H, Niki T, Sohara Y, Sugiyama Y, Mano H: Identification of the transforming EML4-ALK fusion gene in non-small-cell lung cancer. Nature 2007, 448(7153):561-566.

9. Rikova K, Guo A, Zeng Q, Possemato A, Yu J, Haack H, Nardone J, Lee K, Reeves C, Li Y, Hu Y, Tan Z, Stokes M, Sullivan L, Mitchell J, Wetzel R, Macneill J, Ren JM, Yuan J, Bakalarski CE, Villen J, Kornhauser JM, Smith B, Li D, Zhou X, Gygi SP, Gu TL, Polakiewicz RD, Rush J, Comb MJ: Global survey of phosphotyrosine signaling identifies oncogenic kinases in lung cancer. Cell 2007, 131(6):1190-1203.

10. Steuer CE, Ramalingam SS: ALK-positive non-small cell lung cancer: Mechanisms of resistance and emerging treatment options. Cancer 2014, 120(16):2392-2402.

11. Miyanaga A, Shimizu K, Noro R, Seike M, Kitamura K, Kosaihira S, Minegishi Y, Shukuya T, Yoshimura A, Kawamoto M, Tsuchiya S, Hagiwara K, Soda M, Takeuchi K, Yamamoto N, Mano H, Ishikawa Y, Gemma A: Activity of EGFRtyrosine kinase and ALK inhibitors for EML4-ALK-rearranged non-smallcell lung cancer harbored coexisting EGFR mutation. BMC Cancer 2013, 13:262.

12. Chen X, Zhou JY, Zhao J, Chen JJ, Ma SN: Crizotinib overcomes hepatocyte growth factor-mediated resistance to gefitinib in EGFR- mutant non-small-cell lung cancer cells. Anticancer Drugs 2013, 24(10):1039-1046.

13. Berge EM, Lu X, Maxson D, Baron AE, Gadgeel SM, Solomon BJ, Doebele RC, Varella-Garcia M, Camidge DR: Clinical benefit from pemetrexed before and after crizotinib exposure and from crizotinib before and after pemetrexed exposure in patients with anaplastic lymphoma kinasepositive non-small-cell lung cancer. Clin Lung Cancer 2013, 14(6):636-643.

14. Kwak EL, Bang YJ, Camidge DR, Shaw AT, Solomon B, Maki RG, Ou SH, Dezube BJ, Janne PA, Costa DB, Varella-Garcia M, Kim WH, Lynch TJ, Fidias P, Stubbs H, Engelman JA, Sequist LV, Tan W, Gandhi L, Mino-Kenudson M, Wei GC, Shreeve SM, Ratain MJ, Settleman J, Christensen JG, Haber DA Wilner K, Salgia R, Shapiro Gl, Clark JW, et al: Anaplastic lymphoma kinase inhibition in non-small-cell lung cancer. N Engl J Med 2010, 363(18):1693-1703.

15. Frampton JE: Crizotinib: a review of its use in the treatment of anaplastic lymphoma kinase-positive, advanced non-small cell lung cancer. Drugs 2013, 73(18):2031-2051.

16. Casaluce F, Sgambato A, Maione P, Rossi A, Ferrara C, Napolitano A, Palazzolo G, Ciardiello F, Gridelli C: ALK inhibitors: a new targeted therapy in the treatment of advanced NSCLC. Target Oncol 2013, 8(1):55-67.

17. Moher D, Cook DJ, Eastwood S, Olkin I, Rennie D, Stroup DF: Improving the quality of reports of meta-analyses of randomised controlled trials: the QUOROM statement. Quality of Reporting of Meta-analyses. Lancet 1999, 354(9193):1896-1900.

18. Hunter JE, Schmidt FL: Fixed effects vs. random effects meta-analysis models: implications for cumulative research knowledge. Int I Sel Assess 2000, 8(4):275-292.

19. Camidge DR, Bang YJ, Kwak EL, lafrate AJ, Varella-Garcia M, Fox SB, Riely GJ, Solomon B, Ou SH, Kim DW, Salgia R, Fidias P, Engelman JA, Gandhi L, Jänne PA, Costa DB, Shapiro Gl, Lorusso P, Ruffner K, Stephenson P, Tang Y, Wilner K, Clark JW, Shaw AT: Activity and safety of crizotinib in patients with ALK-positive non-small-cell lung cancer: updated results from a phase 1 study. Lancet Oncol 2012, 13(10):1011-1019.

20. Shaw AT, Yeap BY, Solomon BJ, Riely GJ, Gainor J, Engelman JA, Shapiro Gl, Costa DB, Ou SH, Butaney M, Salgia R, Maki RG, Varella-Garcia M, Doebele RC, Bang YJ, Kulig K, Selaru P, Tang Y, Wilner KD, Kwak EL, Clark JW, lafrate AJ, Camidge DR: Effect of crizotinib on overall survival in patients with advanced non-small-cell lung cancer harbouring ALK gene rearrangement: a retrospective analysis. Lancet Oncol 2011, 12(11):1004-1012.

21. Shaw AT, Kim DW, Nakagawa K, Seto T, Crino L, Ahn MJ, De Pas T, Besse B, Solomon BJ, Blackhall F, Wu YL, Thomas M, O'Byrne KJ, Moro-Sibilot D, Camidge DR, Mok T, Hirsh V, Riely GJ, lyer S, Tassell V, Polli A, Wilner KD, Jänne PA: Crizotinib versus chemotherapy in advanced ALK-positive lung cancer. N Engl J Med 2013, 368(25):2385-2394.

22. Brosnan EM, Weickhardt AJ, Lu X, Maxon DA, Baron AE, Chonchol M, Camidge DR: Drug-induced reduction in estimated glomerular filtration rate in patients with ALK-positive non-small cell lung cancer treated with the ALK inhibitor crizotinib. Cancer 2013, 120(5):664-674.

23. Riely GJ, Evans TL, Salgia R, Ou SI, Gettinger SN, Otterson GA, Lanzalone S, Polli A, Shaw AT: Results of a global phase II study with crizotinib in advanced ALK-positive non-small cell lung cancer (NSCLC). Paper presented at: the 2012 Chicago Multidisciplinary Symposium in Thoracic Oncology. Chicago, IL: 2012. Abstract 3.

24. O'Bryant CL, Wenger SD, Kim M, Thompson LA: Crizotinib: a new treatment option for ALK-positive non-small cell lung cancer. Ann Pharmacother 2013, 47(2):189-197.

25. Ou SH: Crizotinib: a novel and first-in-class multitargeted tyrosine kinase inhibitor for the treatment of anaplastic lymphoma kinase rearranged non-small cell lung cancer and beyond. Drug Des Devel Ther 2011, 5:471-485.

26. Curran MP: Crizotinib: in locally advanced or metastatic non-small cell lung cancer. Drugs 2012, 72(1):99-107.

\section{doi:10.1186/1471-2407-14-683}

Cite this article as: Qian et al:: The efficacy and safety of crizotinib in the treatment of anaplastic lymphoma kinase-positive non-small cell lung cancer: a meta-analysis of clinical trials. BMC Cancer 2014 14:683. 